\title{
Role of Pituitary Adenylate-Cyclase Activating Polypeptide and Tac1 gene derived tachykinins in sensory, motor and vascular functions under normal and neuropathic conditions
}

\author{
Bálint Botz ${ }^{\mathrm{a}, \mathrm{c}}$, András Imreh ${ }^{\mathrm{a}}$, Katalin Sándor ${ }^{\mathrm{a}}$, Krisztián Elekes ${ }^{\mathrm{a}}$, János Szolcsányi ${ }^{\mathrm{a}}$, Dóra Reglődi ${ }^{\mathrm{b}}$, \\ John P. Quinn ${ }^{\mathrm{d}}$, James Stewart ${ }^{\mathrm{e}}$, Andreas Zimmer ${ }^{\mathrm{f}}$, Hitoshi Hashimoto ${ }^{\mathrm{g}}$, Zsuzsanna Helyes ${ }^{\mathrm{a}, \mathrm{c}, *}$ \\ a Department of Pharmacology and Pharmacotherapy, University of Pécs, H-7624 Pécs, Szigeti u. 12, Hungary \\ ${ }^{\mathrm{b}}$ Department of Anatomy, PTE-MPTE-MTA Lendulet PACAP Research Team, Faculty of Medicine, University of Pécs, H-7624 Pécs, Szigeti u. 12, Hungary \\ c János Szentágothai Research Center, University of Pécs, H-7624 Pécs, Ifjúság u. 20, Hungary \\ d Department of Molecular and Clinical Pharmacology, Institute of Translational Medicine, Liverpool University, Liverpool, UK \\ e School of Infection and Host Defense, University of Liverpool, UK \\ ${ }^{\mathrm{f}}$ Laboratory of Molecular Neurobiology, Department of Psychiatry, University of Bonn, Bonn, Germany \\ g Graduate School of Pharmaceutical Sciences, Osaka University, Japan
}

\section{A R T I C L E I N F O}

\section{Article history:}

Received 21 January 2013

Received in revised form 4 March 2013

Accepted 4 March 2013

Available online 13 March 2013

\section{Keywords:}

Traumatic mononeuropathy

Sciatic nerve ligation

Mechanical hyperalgesia

Neurogenic vasodilation

Substance P

Tachykinin $\mathrm{NK}_{1}$ receptor

\begin{abstract}
A B S T R A C T
Pituitary Adenylate-Cyclase Activating Polypeptide (PACAP) and Tac1 gene-encoded tachykinins (substance P: SP, neurokinin A: NKA) are expressed in capsaicin-sensitive nerves, but their role in nociception, inflammation and vasoregulation is unclear. Therefore, we investigated the function of these neuropeptides and the $\mathrm{NK}_{1}$ tachykinin receptor (from Tacr1 gene) in the partial sciatic nerve ligationinduced traumatic mononeuropathy model using gene deficient ( $\mathrm{PACAP}^{-1-}, \mathrm{Tac}^{-1-}$, and $\mathrm{Tacr} 1^{-1-}$ ) mice. Mechanonociceptive threshold of the paw was measured with dynamic plantar aesthesiometry, motor coordination with Rota-Rod and cutaneous microcirculation with laser Doppler imaging. Neurogenic vasodilation was evoked by mustard oil stimulating sensory nerves. In wildtype mice $30-40 \%$ mechanical hyperalgesia developed one week after nerve ligation, which was not altered in Tac1 $1^{-1-}$ and Tacr $1^{-{ }^{-}}$ mice, but was absent in PACAP ${ }^{-1-}$ animals. Motor coordination of the PACAP $^{-l-}$ and $\mathrm{Tac}^{-1-}$ groups was significantly worse both before and after nerve ligation compared to their wildtypes, but it did not change in Tacr1 $1^{-1-}$ mice. Basal postoperative microcirculation on the plantar skin of PACAP ${ }^{-1-}$ mice did not differ from the wildtypes, but was significantly lower in Tac1 $1^{-1-}$ and Tacr1 $1^{-1-}$ ones. In contrast, mustard oil-induced neurogenic vasodilation was significantly smaller in $\mathrm{PACAP}^{-1-}$ mice, but not in Tacr $1^{-1-}$ and Tac1 ${ }^{-1-}$ animals. Both PACAP and SP/NKA, but not $\mathrm{NK}_{1}$ receptors participate in normal motor coordination. Tachykinins maintain basal cutaneous microcirculation. PACAP is a crucial mediator of neuropathic mechanical hyperalgesia and neurogenic vasodilation. Therefore identifying its target and developing selective, potent antagonists, might open promising new perspectives for the treatment of neuropathic pain and vascular complications.
\end{abstract}

(c) 2013 Elsevier Inc. All rights reserved.

\section{Introduction}

Painful neuropathy is a very important clinical problem, particularly with the growth of an elderly population, the number of

Abbreviations: PACAP, Pituitary Adenylate Cyclase-Activating Polypeptide; DRG, Dorsal, Root Ganglion; SP, substance P; CGRP, calcitonin gene-related peptide; Tac14, tachykinin-encoding genes; VIP, vasoactive intestinal peptide; NKA, neurokinin A; TRPA1, Transient Receptor Potential Ankyrin 1 receptor.

* Corresponding author at: Department of Pharmacology and Pharmacotherapy, University of Pécs, Pécs 7624, Szigeti u. 12, Hungary. Tel.: +36 72 536001/5386/5591; fax: +3672536218.

E-mail address: zsuzsanna.helyes@aok.pte.hu (Z. Helyes). people affected by these conditions is increasing. Its therapy is an emerging issue, because even with the latest developments on the field of analgesic-research, it is still not satisfactory.

Pituitary Adenylate Cyclase-Activating Polypeptide (PACAP) and tachykinins, such as substance $P$ released from the capsaicinsensitive peptidergic sensory nerves were shown to be involved in acute and chronic pain conditions [2,6,8,42,45,48,52], but their role in chronic neuropathic pain syndromes has not yet been clearly elucidated.

PACAP belongs to the vasoactive intestinal polypeptide (VIP)/secretin/glucagon family [31]. It is present in 27 and 38 aminoacid-containing forms, the latter is more predominant in mammals. So far three receptors of this peptide have been cloned, 
all of which belong to the family of G-protein coupled receptors mediating their effect through the activation of adenylate cyclase and phospholipase C. PACAP is the main endogenous agonist on the PAC1 receptor, whereas PACAP and VIP have similar affinities for the VPAC1 and VPAC2 receptors [22]. The PAC1 receptor is expressed mainly on neural and smooth muscle cells, while the VPAC1/VPAC2 are localized principally on the dorsal root ganglia (DRG), sensory nerve endings, and inflammatory cells $[6,9,50,55,64]$. The fact, that PACAP shows increased expression in the superficial layer of the spinal dorsal horn and in capsaicin-sensitive primary sensory neurons, suggested that it has a role in nociception [33,34,39,61-63]. However, the results obtained from the early in vivo studies proved to be contradictory [41]. Intrathecally administered PACAP-38 showed analgesic effect in the early phase, subsequently followed by a long-lasting algesia in the formalin test [48]. In several other models centrally applied PACAP showed marked pro-nociceptive effects: it decreased thermal stimulation-evoked paw withdrawal latencies and potentiated nociceptive transmission to the dorsal horn [37]. It facilitated spinal nociceptive flexor reflexes $[41,60]$ and induced hyperalgesia [35]. We provided evidence that PACAP-38 exerts an interesting divergent effect on pain-signaling. Peripherally administrated PACAP induces anti-nociceptive, anti-hyperalgesic and anti-allodynic effects in both acute somatic and visceral pain models. However, it does not affect mechanical hyperalgesia in the traumatic mononeuropathy model, but induces sensitization of knee joint primary afferents [42]. Furthermore, PACAP inhibits the release of several pro-nociceptive and pro-inflammatory sensory neuropeptides (CGRP, SP and other tachykinins) from peripheral terminals of capsaicin-sensitive nerves, and it diminishes acute neurogenic and non-neurogenic inflammatory processes $[10,17,36]$. We also described, that PACAP has a dual role in nociception. Thermal allodynia mediated only by peripheral mechanisms is increased in PACAP gene-deficient animals, but somatic and visceral nocifensive behaviors, and neuropathic mechanical hyperalgesia are diminished. This demonstrates that PACAP can have both inhibitory and excitatory roles depending on the site of action and the predominant mechanism in the pain model [44].

Tachykinins represent one of the largest families of neuropeptides released from the capsaicin-sensitive sensory nerve terminals. All of these peptides are relatively small, their average length is $10-11$ aminoacids. So far three tachykinin encoding genes have been cloned (Tac1, Tac3, and Tac4), but the number of the tachykinins is much larger due to post-translational modifications [26,38]. The first identified preprotachykinin-A (PPTA; Tac1) gene encodes substance $\mathrm{P}$ (SP) and Neurokinin-A (NKA). This gene is expressed predominantly in sensory neurons, inflammatory and immune cells [40]. SP and NKA exert a variety of effects under both normal and pathophysiological conditions. They induce neurogenic inflammation (vasodilation, plasma protein extravasation, and stimulation of inflammatory cells), elicit smooth muscle contraction, regulate vascular tone, mucus secretion and immune functions [26]. They induce the release of histamine and serotonin through mast cell activation, which in turn increases the neuropeptide-release from the sensory nerve terminals through positive feedback mechanisms [18,51].

Three tachykinin receptors have been cloned, the Neurokinin 1 , 2 , and $3\left(\mathrm{NK}_{1} ; \mathrm{NK}_{2} ; \mathrm{NK}_{3}\right.$, respectively), which are Gs/Gq-protein coupled [26]. While all tachykinins can activate all receptors, SP and NKA are the preferred ligands for the $\mathrm{NK}_{1}$ and $\mathrm{NK}_{2}$ receptors $[15,23,27]$. The involvement of the Tac1 gene-encoded tachykinins in several models of chronic inflammation and pain has been suggested [13]. SP and NKA are synthesized in the dorsal root ganglia, and they are involved in the regulation of nociceptive information at the first sensory synapse in the spinal cord [7,56]. SP, $\mathrm{NKA}$, and the $\mathrm{NK}_{1}$ receptor have been suggested to be involved in inflammatory and neuropathic pain syndromes, such as traumatic mononeuropathies [2,11,12], streptozotocin-induced diabetes [5], and paclitaxel-induced peripheral neuropathy [52]. However, in these studies only the alterations of $\mathrm{NK}_{1}$ receptor expression was investigated or the effect of non-peptide $\mathrm{NK}_{1}$ receptor antagonists were analyzed, as Tac1 and $\mathrm{NK}_{1}$ gene deficient animals were until recently not available.

Since PACAP and tachykinins are co-localized in capsaicinsensitive afferents, our aim was to elucidate their roles in a model of traumatic mononeuropathy with the help of gene-deleted mice. Furthermore, the involvement of the $\mathrm{NK}_{1}$ receptor, the main target of SP, was also investigated. In order to have an integrative approach, different functional techniques to assess neuropathic mechanical hyperalgesia, motor coordination, and neurogenic vasodilation were used.

\section{Materials and methods}

\subsection{Animals}

Experiments were performed with PACAP, Tac1 and Tacr1 gene-deficient $\left(\mathrm{PACAP}^{-1-}\right.$, Tac1 ${ }^{-1-}$ and Tacr $1^{-1-}$ ) mice and their respective, appropriate wildtype counterparts. The generation of PACAP $^{-1-}$ mice on the CD1 background at the Osaka University has been previously described in details [14]. The heterozygous mice $\left(\mathrm{PACAP}^{+/-}\right)$were backcrossed for 10 generations with the $\mathrm{CD} 1$ strain. After genotyping the offsprings of the first generation of the $\mathrm{PACAP}^{+/-}$breeding pairs, mice were bred on as wildtype $\left(\mathrm{PACAP}^{+/+}\right)$and homozygous gene-deleted (PACAP $\left.{ }^{-/-}\right)$lines in the Laboratory Animal House of the Department of Pharmacology and Pharmacotherapy of the University of Pécs. Offsprings within the first three generations were used for the experiments to minimize genetic variations. The SP and NKA deficient (Tac1 ${ }^{-1-}$ ) and $\mathrm{NK}_{1}$ receptor gene-deleted (Tacr1 ${ }^{-l-}$ ) mice were generated on the C57Bl/6 background at the University of Liverpool and the University of Bonn, respectively, as previously described [16]. The homozygous gene-deleted animals were backcrossed for8-10 generations to the $\mathrm{C} 57 \mathrm{Bl} / 6$ strain, therefore, these mice were used as wildtype (WT) controls. Their original breeding pairs were purchased from Charles-River Ltd. (Hungary). Mice were bred and kept in the Laboratory Animal House of the Department of Pharmacology and Pharmacotherapy of the University of Pécs at $24-25^{\circ} \mathrm{C}$ and provided with standard mouse chow and water ad libitum under $12 \mathrm{~h}$ light and $12 \mathrm{~h}$ dark cycles. All experimental procedures were carried out according to the 1998/XXVIII Act of the Hungarian Parliament on Animal Protection and Consideration Decree of Scientific Procedures of Animal Experiments (243/1988) and complied with the recommendations of the International Association for the Study of Pain [65] and the Helsinki Declaration. The studies were approved by the Ethics Committee on Animal Research of the University of Pécs according to the Ethical Codex of Animal Experiments and license was given (License No.: BA 02/2000-9-2011).

\subsection{The traumatic mononeuropathy model}

Anesthesia was performed with a combination of $100 \mathrm{mg} / \mathrm{kg}$ ketamine i.p. (Richter Gedeon Plc., Budapest, Hungary) and $5 \mathrm{mg} / \mathrm{kg}$ xylazine i.m. (Lavet Ltd., Budapest, Hungary). Then the right common sciatic nerve was unilaterally exposed high in the thigh and its $1 / 3$ was tightly ligated using an atraumatic siliconized silk suture (Ethicone 10-0) [28,47]. Thereafter the wound was closed, and the animals were not examined for the next 7 days in order not to disturb the healing process. In accordance with our previous studies $[42,44]$, this is a reliable model of neuropathic mechanical hyperalgesia, which is not influenced by an impaired weight distribution. 


\subsection{Determination of the mechanonociceptive threshold by dynamic plantar aesthesiometry}

The mechanonociceptive threshold of plantar surface of the hindpaw was measured by dynamic plantar aesthesiometry (Ugo Basile 37400, Comerio, Italy). In this device the animals can freely move in their separate compartments on a metal mesh. Prior to each measurement there was $10-15$ min of acclimation period until the cessation of the animals exploratory behavior. Then the stimulator unit of the device was placed under the animal's paw, using an adjustable angled-mirror to aid the positioning of the metal filament right below the plantar surface. Then an electrodynamic actuator of proprietary design lifted the straight metal filament, which touched the plantar surface and began exerting an increasing upward force at a preset rate $(5 \mathrm{~s})$ of application until either the nocifensive behavior (removal of the paw) was attained, or until the maximal $10 \mathrm{~g}$ was reached. After a conditioning and 3 control preoperative measurements, the paw withdrawal thresholds were determined on days $7,10,14,19$ after the nerve ligation.

\subsection{Assessment of the motor coordination on a Rota-Rod}

Motor functions were studied using an accelerating Rota-Rod device (Ugo Basile 7750, Comerio, Italy). This instrument consists of a constantly faster rotating drum, which is divided into four separate compartments, each for a single animal. Before the beginning of the experiment, we performed 3 training measurements on three consecutive days. The motor performance was indicated by the duration of time (s) spent on the rotating drum [43]. Every measurement was repeated 5 times for each animal, and their means were used for evaluation.

\subsection{Measurement of cutaneous microcirculation by laser Doppler scanning}

Microcirculation in the plantar skin of the hindpaw was measured by laser doppler imaging (Perimed PIM II, Stockholm, Sweden). The mechanism of this device is based on the Dopplerprinciple, as it emits a monochromatic (wave length: $670 \mathrm{~nm}$ ) laser beam, which is reflected from the moving red blood cells. As the reflected laser beam passes through Doppler-shift, detecting its wave-length allows us to measure the rate of blood flow in the superficial capillaries. Because most of the laser light is absorbed in the superficial tissues, the blood flow of the larger blood vessels does not disturb the measurement. Mice were anesthetized with urethane $(2.4 \mathrm{~g} / \mathrm{kg}$ i.p.), their body temperature was maintained at $37^{\circ} \mathrm{C}$ with a controlled heating pad. At the beginning of the experiment 3-4 control images of the plantar surfaces of both the operated and the intact contralateral hindpaws were taken simultaneously to obtain stable baseline flow data. Then 30-30 $\mu$ l of 5\% mustard-oil (allyl-isothiocyanate) was applied topically on both plantar surfaces to induce neurogenic vasodilatation. This chemical compound is a Transient Receptor Potential Ankyrin 1 (TRPA1) receptor agonist, therefore, it induces the release of vasoactive neuropeptides from the intact sensory nerve endings, which in turn leads to an increased blood flow in the innervated area (neurogenic vasodilation). The plantar microcirculation was measured for $60 \mathrm{~min}$ after mustard oil application. Altogether an average of 30 images were recorded for each animal including the initial control measurements. $5 \%$ mustard-oil was prepared freshly before the beginning of the experiment from the same concentrated solution. All knockout and wildtype mice were measured within a time limit of $48 \mathrm{~h}$ to decrease the possible environmental interferences.

\subsection{Statistical analysis}

All data were expressed as means with standard errors of means (s.e.m.). For statistical evaluation repeated measures ANOVA followed by Bonferroni's modified $t$-test was used for the assessment of mechanical hyperalgesia and motor performance, whereas the results of the laser doppler imaging were evaluated using twoway ANOVA and Bonferroni's modified $t$-test. When comparing the results * $p<0.05$ was considered statistically significant.

\section{Results}

\subsection{Mechanical hyperalgesia in response to partial ligation of the} sciatic nerve

The initial control mechanonociceptive thresholds of PACAP ${ }^{-1-}$ mice were similar to the wildtypes. Tight ligation of $1 / 3$ of the sciatic nerve induced a significant, about $30-40 \%$ decrease of the threshold of the affected hindpaw in wildtype animals between the 7th and 19th postoperative days. In comparison, neuropathic mechanical hyperalgesia was minimal in the $\mathrm{PACAP}^{-/-}$group, the nociceptive threshold remained similar to the initial control values throughout the total duration of the experiment (Fig. 1A).

The preoperative mechanonociceptive thresholds of $\mathrm{C} 57 \mathrm{Bl} / 6$ wildtype mice did not differ significantly from either the $\mathrm{PACAP}^{+/+}$ wildtypes generated on the CD1 background or the Tac $1^{-/-}$and the Tacr1 $1^{-l}$ ones. Furthermore, the $35-45 \%$ mechanical hyperalgesia detected in response to the nerve ligation was also very similar in all the three groups, SP/NKA or $\mathrm{NK}_{1}$ receptor deficiency did not influence its development during the whole study (Fig. 1B and C).

\subsection{Changes of the motor functions}

The basal motor performance on the accelerating Rota-Rod was significantly worse in both the PACAP ${ }^{-1-}$ and Tac1 $1^{-l-}$ groups compared to the respective wildtypes (Fig. $2 \mathrm{~A}$ and $\mathrm{B}$ ). In contrast, deletion of the $\mathrm{NK}_{1}$ tachykinin receptor (Tacr $1^{-/-}$) did not influence the motor coordination (Fig. 2C). The partial sciatic nerve ligation did not influence the motor coordination in any of the groups. During the control pre-operative and even the post-operative periods a continuous learning process was observed in the wildtype and the PACAP and Tac1 gene-deleted groups, but not in Tacr1 $1^{-1-}$ animals. However, the basal impaired motor coordination in PACAP $^{-1-}$ and Tac1 ${ }^{-1-}$ mice was also observed after the operation (Fig. 2A and B).

\subsection{Changes of cutaneous blood flow and neurogenic vasodilation}

In both wildtype (PACAP ${ }^{++}$and $\left.\mathrm{C} 57 \mathrm{Bl} / 6\right)$ and all the three gene-deficient $\left(\mathrm{PACAP}^{-1-}, \mathrm{Tac}^{-1-}, \mathrm{Tacr}^{-1-}\right.$ ) groups, the basal microcirculation in the plantar skin was reduced on the operated limb, but the difference was not statistically significant. The basal perfusion was significantly higher in the black $\mathrm{C} 57 \mathrm{Bl} / 6$, Tac1-/-, but not Tacr $1^{-/-}$mice as compared to the white PACAP $^{+/+}$and PACAP $^{-/-}$ ones generated on the CD1 background. Meanwhile, topical application of $5 \%$ mustard oil activating the capsaicin-sensitive sensory nerve terminals in the skin and inducing neuropeptide release evoked significantly smaller neurogenic vasodilator response in the C57Bl/6-based groups compared to the CD1-based ones (15-20\% vs. $50-60 \%)$. This clearly indicates a remarkable strain difference in the regulation of microcirculation (Figs. 3-5).

Basal perfusion in the plantar skin of both the operated and intact limbs of $\mathrm{PACAP}^{+/+}$and $\mathrm{PACAP}^{-/-}$mice did not differ significantly $(3.4 \pm 0.32 \mathrm{~V}$, vs. $3.97 \pm 1.04 \mathrm{~V})$. In response to activation of the capsaicin-sensitive sensory nerve terminals by topical application of $5 \%$ mustard oil microcirculation similarly increased by 
A

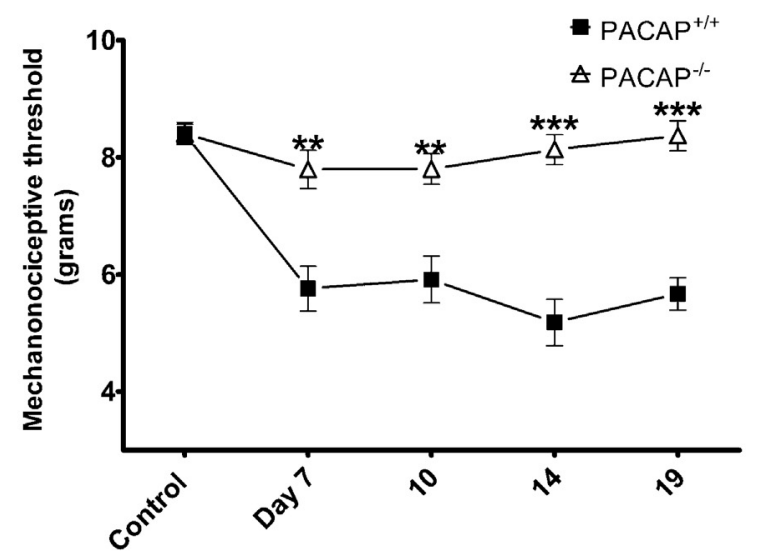

B

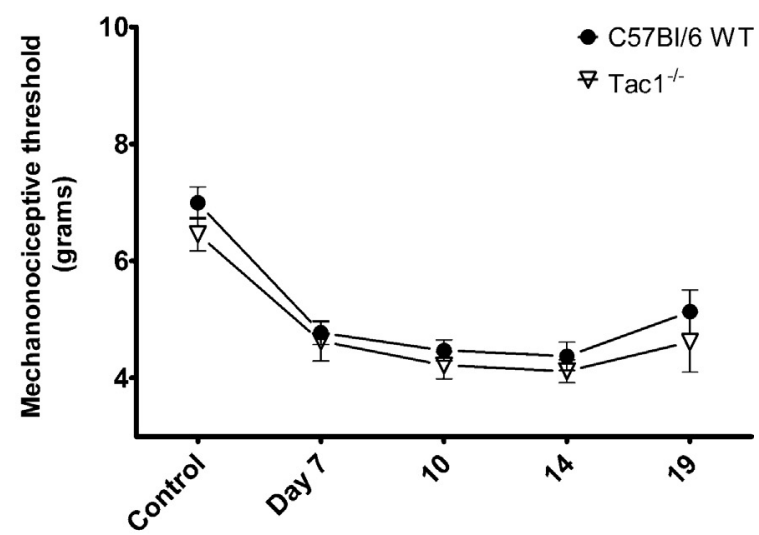

C

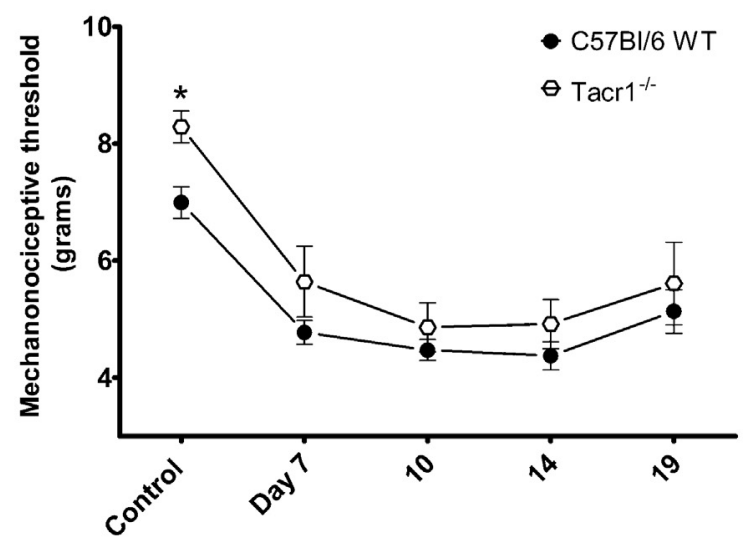

Days after sciatic nerve ligation

Fig. 1. Changes of mechanonociceptive threshold of the paw after partial sciatic nerve ligation in (A) PACAP gene-deficient ( $\mathrm{PACAP}^{-1-}$ ) mice compared to their wildtypes $\left(\mathrm{PACAP}^{+/+}\right.$) generated on the $\mathrm{CD} 1$ background, as well as in (B) Tac1 gene-deleted animals (Tac1 $1^{-1-}$ ) lacking substance $P$ and neurokinin $A$, and (C) NK1 tachykinin receptor deficient (Tacr1 ${ }^{-1-}$ ) mice in comparison with their C57Bl/6 wildtype (WT) counterparts. Data points represent means of $n=12$ per group with s.e.m.; ${ }^{* *} p<0.01,{ }^{* * *} p<0.001$ vs. respective wildtype control (repeated measures ANOVA + Bonferroni's modified $t$-test).

$50-60 \%$ in both groups on both sides after $5-10 \mathrm{~min}$. This neurogenic vasodilation response persisted in wildtype mice during the next 60 min of the experiment, whereas in PACAP $^{-1-}$ animals it started to decrease after $10-15$ min Significantly lower perfusion

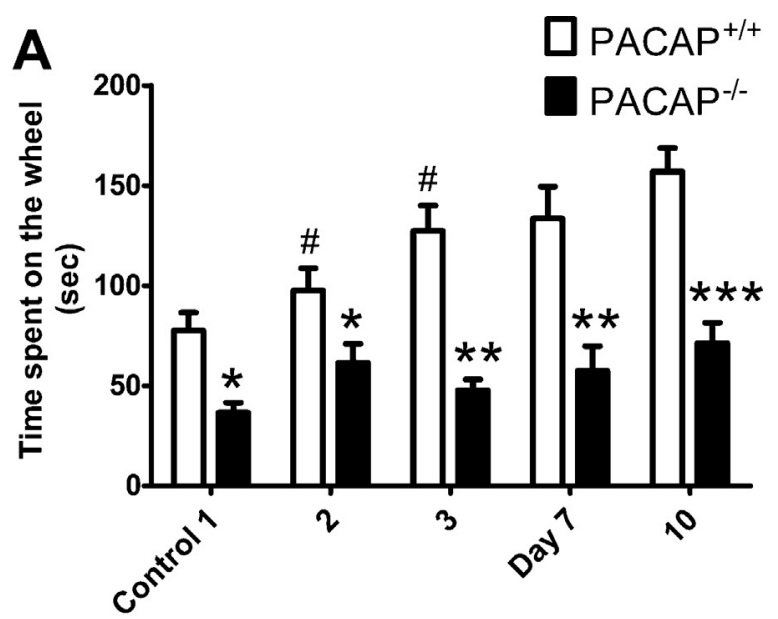

B
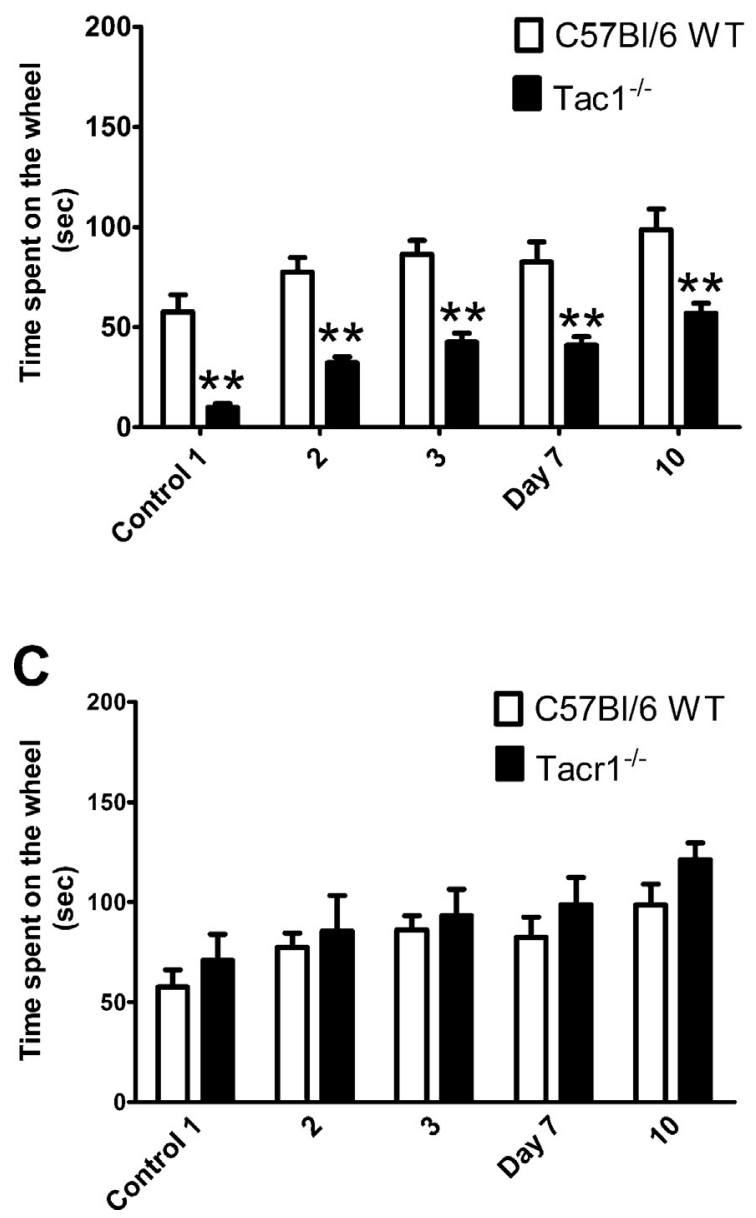

Fig. 2. Motor performance on the accelerating Rota-Rod wheel before and on the 7 th and 10th postoperative days after sciatic nerve ligation in (A) PACAP gene-deficient $\left(\mathrm{PACAP}^{-/-}\right.$) mice compared to their wildtypes $\left(\mathrm{PACAP}^{+/+}\right)$generated on the CD1 background, as well as in (B) Tac1 gene-deleted animals (Tac1 ${ }^{-l-}$ ) lacking substance $P$ and neurokinin $\mathrm{A}$, and $(\mathrm{C}) \mathrm{NK}_{1}$ tachykinin receptor deficient (Tacr1 ${ }^{-1-}$ ) mice in comparison with their C57Bl/6 wildtype (WT) counterparts. Columns represent means of $n=6-12$ per group with s.e.m.; ${ }^{*} p<0.05,{ }^{* *} p<0.01,{ }^{* * *} p<0.001$ vs. respective wildtype control; $\# p<0.05$ vs. respective day 1 preoperative value (repeated measures ANOVA+Bonferroni's modified $t$-test).

was detected in the PACAP ${ }^{-1-}$ group from the 30th minute of the measurement (Figs. 3 and $4 \mathrm{~A}$ and $\mathrm{B}$ ).

In the Tac $1^{-/-}$and Tacr $1^{-1-}$ groups the basal cutaneous microcirculation was significantly lower on both limbs compared to the 

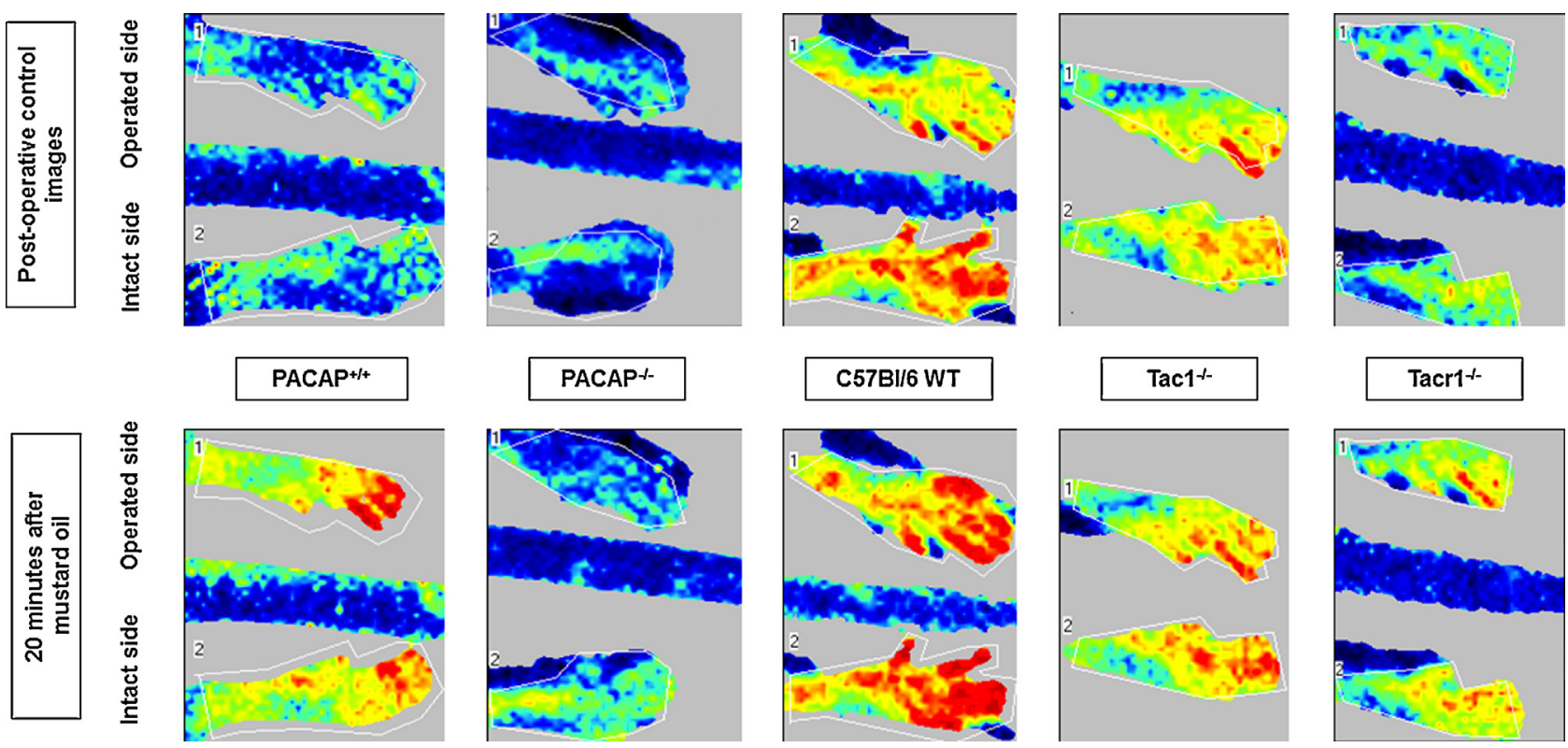

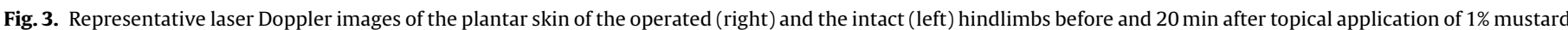

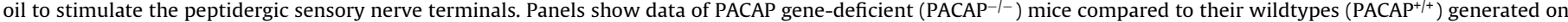

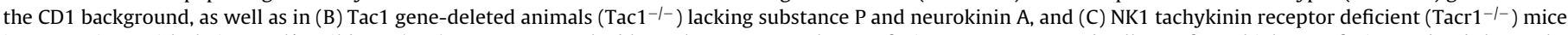

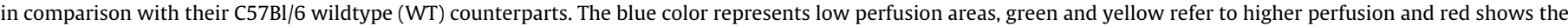
highest microcirculation.

C57Bl/6 wild types (Fig. 5). In response to mustard oil smearing the perfusion increased steadily by $15-20 \%$ on both limbs of the wildtype mice. In contrast, in cases of SP/NKA and NK1 receptor deficiency there was an initial transient decrease on the intact side, but after the first $10 \mathrm{~min}$, the blood perfusion did not differ significantly from the results of the C57Bl/6 wildtype animals for the rest of the experiment (Fig. 5).

\section{Discussion}

These results provide clear evidence that: (1) Under normal conditions PACAP and tachykinins play important roles in motor coordination, but they are not involved in mechanonociception. (2) Tachykinins regulate the basal cutaneous microcirculation through $\mathrm{NK}_{1}$ receptor activation, but PACAP is involved in neurogenic vasodilation. (3) Partial ligation of the sciatic nerve, which is a widely used traumatic mononeuropathy model, induces purely sensory neuropathy (mechanical hyperalgesia) without affecting the motor and the vascular functions. (4) PACAP is a crucial mediator of neuropathic hyperalgesia.

Our earlier data showing that PACAP has a hyperalgesic and pro-nociceptive role in a variety of pain models are in agreement with the present findings [42]. Others also showed that PACAP might play a key role in spinal sensitization, and therefore, in the development of neuropathic pain $[8,25]$ through PAC1 receptor activation in the dorsal root ganglia $[6,20]$. Furthermore, PACAP is likely to have a pivotal pro-nociceptive function in animal models of migraine and also in human migraneurs [29,46,54]. Others suggested that the peripheral nociceptive responses elicited by intradermally administered PACAP are mainly mediated through the VPAC receptors [45]. Therefore, identification of the targets and the mechanisms of the hyperalgesic actions of PACAP still need further investigations.

While the increased expression of the Tac1 gene-encoded tachykinins in the dorsal root ganglia under neuropathic conditions has been established [57], our results indicate that SP/NKA and the $\mathrm{NK}_{1}$ receptor do not play an important role in the development of neuropathic hyperalgesia. Studying the analgesic mechanisms of the action of topical capsaicin application in neuropathies, it was found that the increased expression of SP has only marginal effect, and capsaicin exerts its therapeutic benefit through other pathways [1]. Other results also indicate that SP/NKA up-regulation is not a crucial factor in the development of neuropathies: while it was found to be involved in the development of paclitaxel-induced neuropathy, oxaliplatin treatment leads to a similar condition without influencing the SP/NKA release [52].

The motor coordination of the PACAP and Tac1 gene deficient animals was significantly worse than their wildtype counterparts under both normal and neuropathic conditions, while the motor performance of the $\mathrm{NK}_{1}$ receptor deficient group was similar to the control animals. These results suggest, that PACAP and SP/NKA might have a potential role as mediators of normal motor coordination. However, this effect of the tachykinins is not mediated through the $\mathrm{NK}_{1}$ receptor, but the action of NKA at the $\mathrm{NK}_{2}$ tachykinin receptor can be suggested. These findings are supported by earlier data showing that PACAP may contribute to the regulation of motor coordination, though the mechanism and the site of action has not been described [30]. Currently there is less data available about the potential role of the Tac 1 gene encoded tachykinins, but the few earlier results obtained in markedly different models (less complex species) also indicate that tachykinins might also affect the motor coordination [21]. SP has been suggested to have a protective role in an animal model of amyotrophic lateral sclerosis, which is due to motor neuron degeneration, supporting its role in motor coordination [3]. SP and the $\mathrm{NK}_{1}$ receptor activation may also have a potential role in the development of Parkinson's disease, in which the loss of motor coordination is the principal symptom. Increased SP expression in this model accelerated disease progression, whereas $\mathrm{NK}_{1}$ receptor antagonist treatment improved the motor performance [53]. The significant mechanical hyperalgesia, but normal motor performance and cutaneous microcirculation observed in response to the sciatic nerve ligation indicates, that although it contains sensory, motor and autonomic fibers, the traumatic mononeuropathy induced by this operative process is exclusively of sensory nature and it does not hinder either the motor performance or the vascular regulation. 

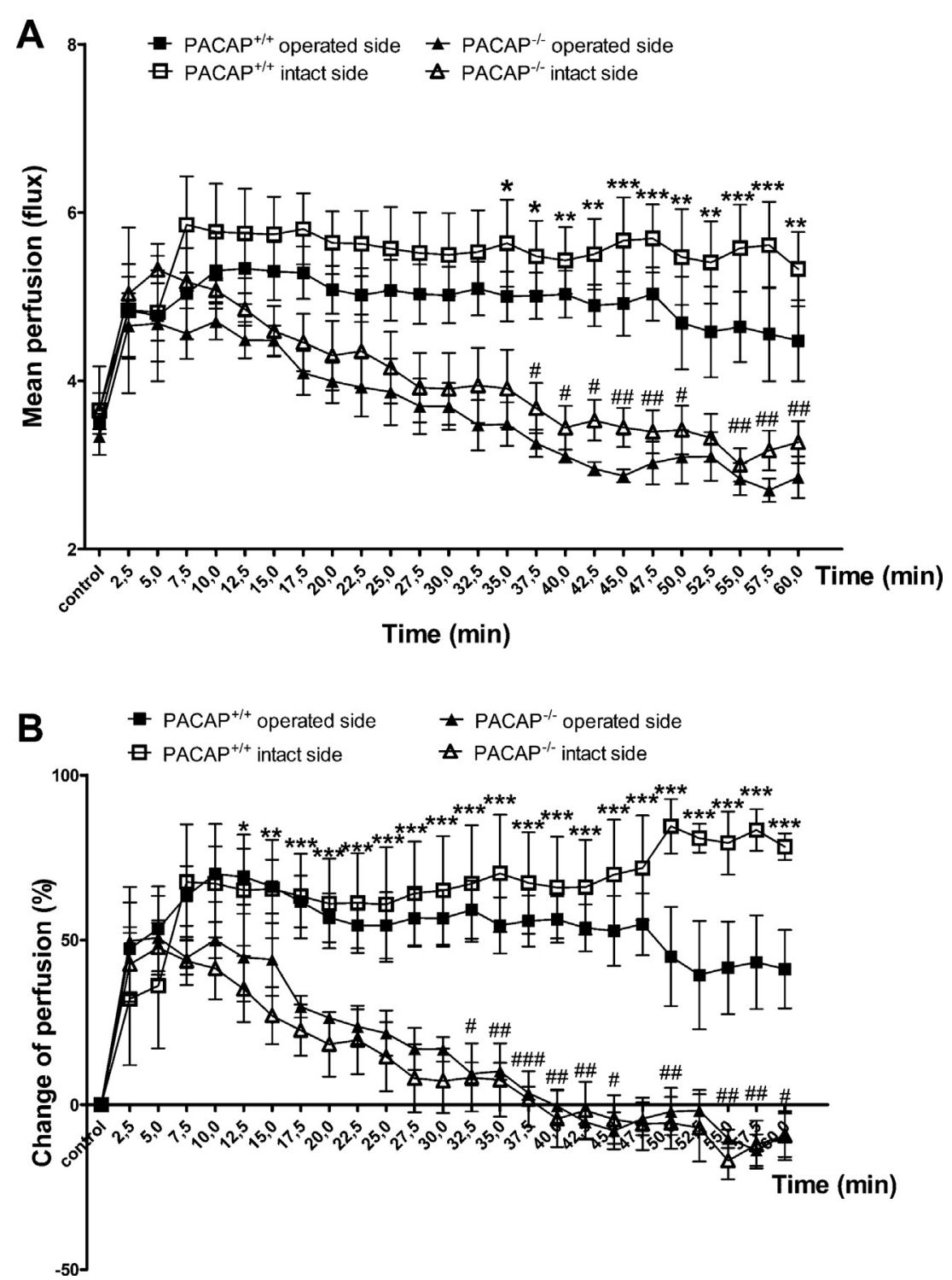

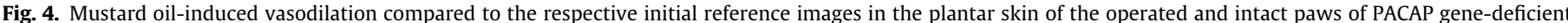

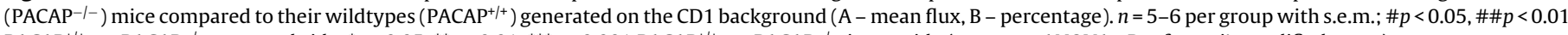
PACAP $^{+/+}$vs. PACAP $-/-$operated side, ${ }^{*} p<0.05,{ }^{* *} p<0.01,{ }^{* * *} p<0.001$ PACAP $^{+/+}$vs. PACAP $-/-$intact side (two-way ANOVA+Bonferroni's modified $t$-test).

Besides neuropathic hyperalgesia, PACAP is involved in the development of neurogenic vasodilation, particularly in its long-term maintenance. As mustard oil activating the capsaicinsensitive afferents predominantly via TRPA1 ion channel activation induced a remarkable initial vasodilation in PACAP deficient mice, which very rapidly decreased, it is suggested, that PACAP contributes to the later, stable phase of neurogenic vasodilation. Other sensory neuropeptides released from the stimulated sensory nerves, such as CGRP are likely to be responsible for the early phase of this response.

As the basal blood flow was significantly lower in both Tac1 and Tacr1 gene-deficient mice, SP through $\mathrm{NK}_{1}$ receptor activation is likely to play an important role in the mediation of the basal vascular tone, it dilates the cutaneous vessels. However, they do not have an important function in neurogenic vasodilation. It should be noted that the well established effect of SP in neurogenic inflammation is increasing venular permeability, a phenomen which was not measured with the laser Doppler scanning [19]. In addition, CGRP is considered as the most potent mediator of vasodilation [24]. It was suggested, that the $\mathrm{NK}_{1}$ receptor activation serves to increase indirectly the production of nitric oxide (NO) and other local vasodilatory substances, however it is accepted, that there is a lot of interactions between the neuropeptides, local mediators, and receptors involved in this process, and the responsible pathways are redundant [59]. It must be taken into account, that SP is not the sole endogenous ligand of the $\mathrm{NK}_{1}$ receptor, on which the other known tachykinins also act as potent agonists, therefore probably bypassing the role of the lacking SP/NKA. In addition it is established, that though tachykinins are in most conditions potent vasodilators, in different models or species they can induce vasoconstriction, and that their net effect is heavily influenced by the local differences of the endothelium [58]. This assumption also correlates with the fact, that so far no substance could be labeled as the exclusive mediator of cutaneous vasodilation $[4,24]$.

We found remarkable strain differences between the $\mathrm{C} 57 \mathrm{Bl} / 6$ and $\mathrm{CD} 1$ mice $\left(\mathrm{PACAP}^{+/+}\right)$in the examined sensory, motor and vascular parameters. It is not surprising, since a large number of papers described such findings, and reviews focus on the issue of strain difference $[32,49]$. Describing these differences is in fact valuable, and highlights the importance of using the appropriate wildtypes when 

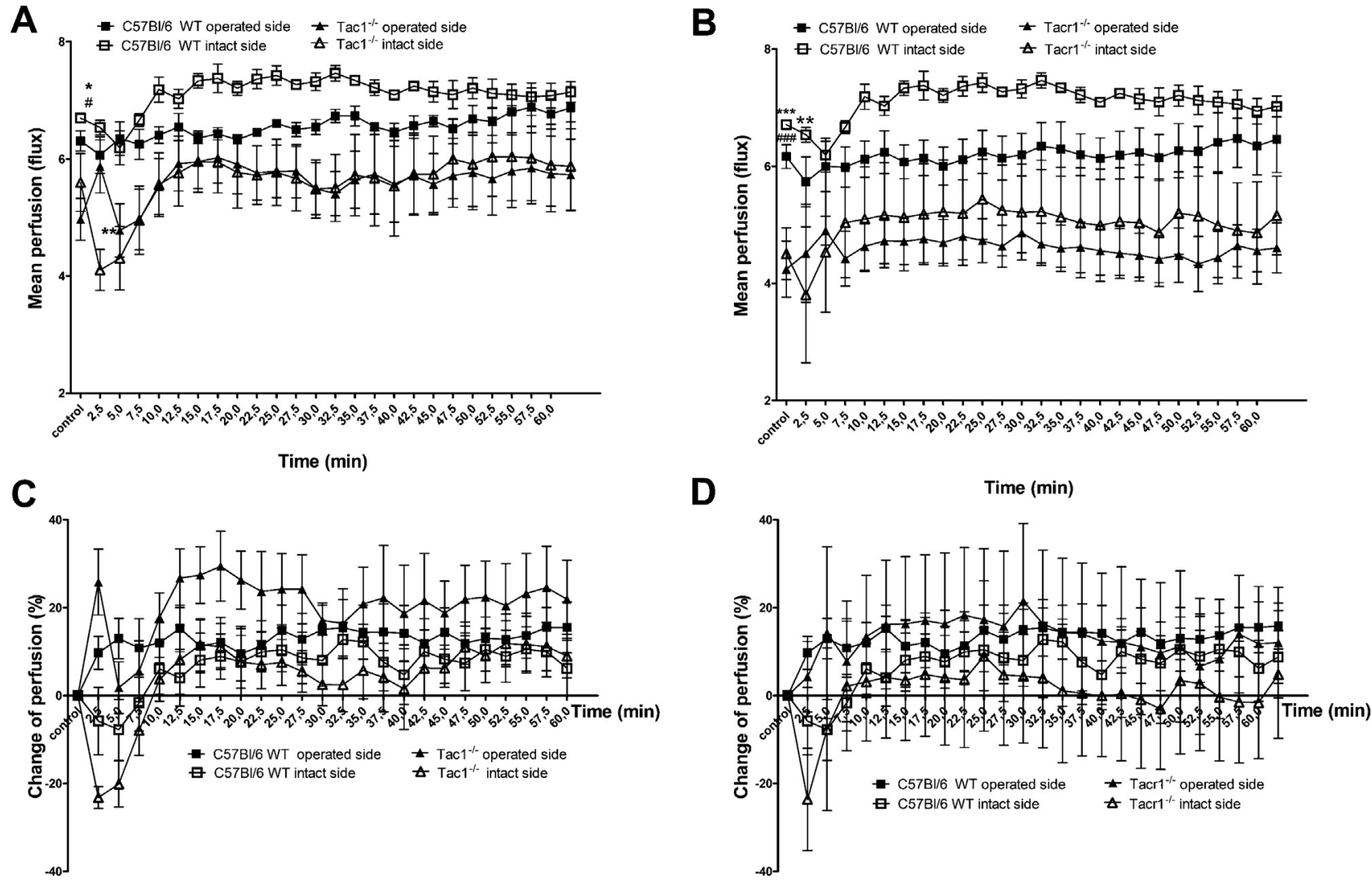

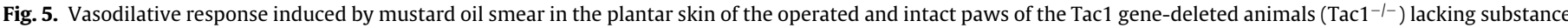

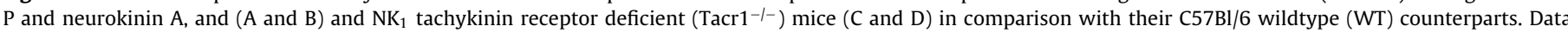

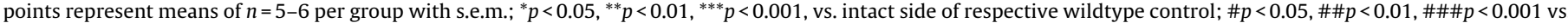
respective operated paw of wildtype control (two-way ANOVA + Bonferroni's modified $t$-test).

interpreting data of gene-deficient mice. In the present experimental series we did not aim to compare the tachykinin and $\mathrm{NK}_{1}$ deficient mice with the PACAP knockouts, but only to compare them with their respective and appropriate wildtypes in order to elucidate their role in the investigated biological functions. The conclusions were drawn from the results separately.

It can be concluded that (1) PACAP has an overall pronociceptive role in peripheral traumatic neuropathy. (2) PACAP and $\mathrm{SP} / \mathrm{NKA}$ are both involved in motor coordination, while the lack of the $\mathrm{NK}_{1}$ receptor does not affect this function. (3) Tac1 gene products and $\mathrm{NK}_{1}$ receptor have a pivotal role in the maintenance of basal vascular tone, whereas PACAP is a key mediator of neurogenic vasodilation, particularly involved in its long-term maintenance.

\section{Acknowledgements}

SROP-4.2.2.A-11/1/KONV-2012-0024, SROP-4.2.1.B-10/2/ KONV-2010-0002, SROP-4.2.2.B-10/1/2010-0029, OTKA K104984, Arimura Foundation, PTE-MTA “Lendület” Program.

\section{References}

[1] Anand P, Bley K. Topical capsaicin for pain management: therapeutic potential and mechanisms of action of the new high-concentration capsaicin $8 \%$ patch. Br J Anaesth 2011;107:490-502.

[2] Cahill CM, Coderre TJ. Attenuation of hyperalgesia in a rat model of neuropathic pain after intrathecal pre- or post-treatment with a neurokinin-1 antagonist. Pain 2002;95:277-85.

[3] Caioli S, Curcio L, Pieri M, Antonini A, Marolda R, Severini C, et al. Substance P receptor activation induces downregulation of the AMPA receptor functionality in cortical neurons from a genetic model of Amyotrophic Lateral Sclerosis. Neurobiol Dis 2011;44:92-101.
[4] Charkoudian N. Mechanisms and modifiers of reflex induced cutaneous vasodilation and vasoconstriction in humans. J Appl Physiol 2010;109:1221-8.

[5] Coudoré-Civiale M, Courteix C, Boucher M, Fialip J, Eschalier A. Evidence for an involvement of tachykinins in allodynia in streptozocin-induced diabetic rats. Eur J Pharmacol 2000;401:47-53.

[6] Davis-Traber R, Baker S, Lehto SG, Zhong C, Surowy CS, Faltynek CR, et al. Central pituitary adenylate cylase 1 receptors modulate nociceptive behaviours in both inflammation and neuropathic pain states. J Pain 2008;9:449-56.

[7] De Koninck Y, Henry JL. Substance P-mediated slow excitatory postsynaptic potential elicited in dorsal horn neurons in vivo by noxious stimulation. Proc Natl Acad Sci USA 1991;88:11344-8.

[8] Dickinson T, Fleetwood-Walker SM. VIP and PACAP: very important in pain? Trends Pharmacol Sci 1999;20:324-9.

[9] Ekblad E. Pharmacological evidence for both neuronal and smooth muscular PAC1 receptors and a VIP-specific receptor in rat colon. Regul Pept 1999;85:87-92.

[10] Elekes K, Sandor K, Moricz A, Kereskai L, Kemeny A, Szoke E, et al. Pituitary adenylate cyclase-activating polypeptide plays an anti-inflammatory role in endotoxin-induced airway inflammation: in vivo study with gene-deleted mice. Peptides 2011;32:1439-46.

[11] Goff JR, Burkey AR, Goff DJ, Jasmin L. Reorganization of the spinal dorsal horn in models of chronic pain: correlation with behaviour. Neuroscience 1998;82:559-74.

[12] Gonzalez MI, Field MJ, Hughes J, Singh L. Evaluation of selective NK1 receptor antagonist CI-1021 in animal models of inflammatory and neuropathic pain. J Pharmacol Exp Ther 2000;294:444-50.

[13] Harrison S, Geppetti P, Substance P. Int J Biochem Cell Biol 2001;33:555-76.

[14] Hashimoto H, Shintani N, Tanaka K, Mori W, Hirose M, Matsuda T, et al. Altered psychomotor behaviors in mice lacking pituitary adenylate cyclase-activating polypeptide (PACAP). Proc Natl Acad Sci USA 2001;98:13355-60.

[15] Hastrup H, Schwartz TW. Septide and neurokinin A are high-affinity ligands on the NK-1 receptor: evidence from homologous versus heterologous binding analysis. FEBS Lett 1996;399:264-6.

[16] Helyes Z, Elekes K, Sandor K, Szitter I, Kereskai L, Pinter E, et al. Involvement of preprotachykinin A gene-encoded peptides and the neurokinin 1 receptor in endotoxin-induced murine airway inflammation. Neuropeptides 2010;44:399-406.

[17] Helyes Zs, Pozsgai G, Borzsei R, Nemeth J, Bagoly T, Mark L, et al. Inhibitory effect of PACAP-38 on acute neurogenic and non-neurogenic inflammatory processes in the rat. Peptides 2007;28:1847-55. 
[18] Holzer P. Capsaicin: cellular targets, mechanisms of action, and selectivity for thin sensory neurons. Pharmacol Rev 1991;43:143-201.

[19] Holzer P. Neurogenic vasodilatation and plasma leakage in the skin. Gen Pharmacol 1998;30:5-11.

[20] Jongsma H, Danielsen N, Sundler F, Kanje M. Alteration of PACAP distribution and PACAP receptor binding in the rat sensory nervous system following sciatic nerve transection. Brain Res 2000;85:186-96.

[21] Kahsai L, Martin JR, Winther AM. Neuropeptides in the Drosophila central complex in modulation of locomotor behavior. J Exp Biol 2010;213:2256-65.

[22] Laburthe M, Couvineau A, Tan V. Class II G-protein-coupled receptors for VIP and PACAP: structure, models of activation and pharmacology. Peptides 2007;28:1631-9.

[23] Lecci A, Maggi CA. Peripheral tachykinin receptors as potential therapeutic targets in visceral diseases. Expert Opin Ther Targets 2003;7:343-62.

[24] Lin Q, Li D, Xu X, Zou X, Fang L. Roles of TRPV1 and neuropeptidergic receptors in dorsal root reflex-mediated neurogenic inflammation induced by intradermal injection of capsaicin. Mol Pain 2007;25(3):30.

[25] Mabuchi T, Shintani N, Matsumura S, Okuda-Ashitaka E, Hashimoto H, Muratani $\mathrm{T}$, et al. Pituitary adenylate cyclase-activating polypeptide is required for the development of spinal sensitization and induction of neuropathic pain. Neuroscience 2004;24:7283-91.

[26] Maggi CA. The mammalian tachykinin receptors. Gen Pharmacol 1995;26:911-44.

[27] Maggi CA, Schwartz TW. The dual nature of the tachykinin NK1 receptor. Trends Pharmacol Sci 1997;18:351-5.

[28] Malmberg AB, Basbaum AI. Partial sciatic nerve injury in the mouse as a model of neuropathic pain: behavioural and neuroanatomical correlates. Pain 1998;76:215-22.

[29] Markovics A, Kormos V, Gaszner B, Lashgarara A, Szoke E, Sandor K, et al. Pituitary adenylate cyclase activating polypeptide plays a key role in nitroglycerol-induced trigeminovascular activation in mice. Neurobiol Dis 2012:45:633-44.

[30] Marquez P, Bebawy D, Lelièvre V, Coûté AC, Evans CJ, Waschek JA, et al. The role of endogenous PACAP in motor stimulation and conditioned place preference induced by morphine in mice. Psychopharmacology (Berlin) 2009;20:457-63.

[31] Miyata A, Arimura A, Dahl RR, Minamino N, Uehara A, Jiang L, et al. Isolation of a novel 38 residue-hypothalamic polypeptide which stimulates adenylate cyclase in pituitary cells. Biochem Biophys Res Commun 1989;164:567-74.

[32] Mogil JS, Wilson SG, Bon K, Lee SE, Chung K, Raber P, et al. Heritability of nociception I: responses of 11 inbred mouse strains on 12 measures of nociception. Pain 1999;80:67-82.

[33] Moller K, Zhang YZ, Hakanson R, Luts A, Sjolund B, Uddman R, et al. Pituitary adenylate cyclase activating peptide is a sensory neuropeptide: immunocytochemical and immunochemical evidence. Neuroscience 1993;57:725-32.

[34] Mulder H, Jongsma H, Zhang YZ, Gebre-Medhin S, Sundler F, Danielsen N. Pituitary adenylate cyclase activating polypeptide and islet amyloid polypeptide in primary sensory neurons: functional implications from plasticity in expression on nerve injury and inflammation. Mol Neurobiol 1999;19:229-53.

[35] Narita M, Dun SL, Dun NJ, Tseng LF. Hyperalgesia induced by pituitary adenylate cyclase activating polypeptide in the mouse spinal cord. Eur J Pharmacol 1996;311:121-6.

[36] Nemeth J, Reglodi D, Pozsgai G, Szabo A, Elekes K, Pinter E, et al. Effect of pituitary adenylate cyclase activating polypeptide-38 on sensory neuropeptide release and neurogenic inflammation in rats and mice. Neuroscience 2006;143:223-30.

[37] Ohsawa M, Brailoiu GC, Shiraki M, Dun NJ, Paul K, Tseng LF. Modulation of nociceptive transmission by pituitary adenylate cyclase activating polypeptide in the spinal cord of the mouse. Pain 2002;100:27-34.

[38] Page NM. New challenges in the study of the mammalian tachykinins. Peptides 2005;26:1356-68.

[39] Pettersson LM, Heine T, Verge VM, Sundler F, Danielsen N. PACAP mRNA is expressed in rat spinal cord neurons. J Comp Neurol 2004;471:85-96.

[40] Pinto FM, Almeida TA, Hernandez M, Devillier P, Advenier C, Candenas ML. mRNA expression of tachykinins and tachykinin receptors in different human tissues. Eur J Pharmacol 2004;494:233-9.

[41] Sakashita Y, Kurihara D, Uchida T, Tatsuno I, Yamamoto T. Involvement of PACAP receptor in primary afferent fibre-evoked responses of ventral roots in the neonatal rat spinal cord. Br J Pharmacol 2001;132:1769-76.
[42] Sandor K, Bolcskei K, McDougall J, Schuelert N, Reglodi D, Elekes K et al. Divergent peripheral effects of pituitary adenylate cyclase activating polypeptide-38 on nociception in rats and mice. Pain 2009;141: 143-50.

[43] Sandor K, Helyes Z, Gyires K, Szolcsányi J, Laszlo J. Static magnetic field-induced anti-nociceptive effect and the involvement of capsaicin-sensitive sensory nerves in this mechanism. Life Sci 2007;81:97-102.

[44] Sándor K, Kormos V, Botz B, Imreh A, Bolcskei K, Gaszner B, et al. Impaired nocifensive behaviours and mechanical hyperalgesia, but enhanced thermal allodynia in pituitary adenylate cyclase-activating polypeptide deficient mice. Neuropeptides 2010;44:363-71.

[45] Schytz HW, Holst H, Arendt-Nielsen L, Olesen J, Ashina M. Cutaneous nociception and neurogenic inflammation evoked by PACAP38 and VIP. J Headache Pain 2010;11:309-16.

[46] Schytz HW, Olesen J, Ashina M. The PACAP receptor: a novel target for migraine treatment. Neurotherapeutics 2010;7:191-6.

[47] Seltzer Z, Dubner R, Shir Y. A novel behavioural model of neuropathic pain disorders produced in rats by partial sciatic nerve injury. Pain 1990;43:205-18.

[48] Shimizu T, Katahira M, Sugawara H, Inoue K, Miyata A. Diverse effects of intrathecal pituitary adenylate cyclase-activating polypeptide on nociceptive transmission in mice spinal cord. Regul Pept 2004;123:117-22.

[49] Smith SB, Crager SE, Mogil JS. Paclitaxel-induced neuropathic hypersensitivity in mice: responses in 10 inbred mouse strains. Life Sci 2004;74: 2593-604.

[50] Somogyvari-Vigh A, Reglodi D. Pituitary adenylate cyclase activating polypeptide: a potential neuroprotective peptide. Curr Pharm Des 2004;10: 2861-89.

[51] Szallasi A, Blumberg PM. Vanilloid (capsaicin) receptors and mechanisms. Pharmacol Rev 1999;51:159-212.

[52] Tatsushima Y, Egashira N, Kawashiri T, Mihara Y, Yano T, Mishima K, et al. Involvement of substance $\mathrm{P}$ in peripheral neuropathy induced by paclitaxel but not oxaliplatin. J Pharmacol Exp Ther 2011;337:226-35.

[53] Thornton E, Vink R. Treatment with a substance P receptor antagonist is neuroprotective in the intrastriatal 6-hydroxydopamine model of early Parkinson's disease. PLoS ONE 2012;7:e34138.

[54] Tuka B, Helyes Z, Markovics A, Bagoly T, Németh J, Márk L, et al. Peripheral and central alterations of pituitary adenylate cyclase activating polypeptide-like immunoreactivity in the rat in response to activation of the trigeminovascular system. Peptides 2012;33:307-16.

[55] Vaudry D, Falluel-Morel A, Bourgault S, Basille M, Burel D, Wurtz O, et al. Pituitary adenylate cyclase-activating polypeptide and its receptors: 20 years after the discovery. Pharmacol Rev 2009;61:283-357.

[56] Vedder H, Otten U. Biosynthesis and release of tachykinins from rat sensory neurons in culture. J Neurosci Res 1991;30:288-99.

[57] Wallin J, Schött E, Substance P. release in the spinal dorsal horn following peripheral nerve injury. Neuropeptides 2002;36:252-6.

[58] Walsh DA, McWilliams FD. Tachykinins and the cardiovascular system. Curr Drug Targets 2006;7:1031-42.

[59] Wong BJ, Minson CT. Neurokinin-1 receptor desensitization attenuates cutaneous active vasodilatation in humans. J Physiol 2006;577:1043-51.

[60] Xu XJ, Wiesenfeld-Hallin Z. Intrathecal pituitary adenylate cyclase activating polypeptide facilitates the spinal nociceptive flexor reflex in the rat. Neuroscience 1996;72:801-4.

[61] Zhang Y, Danielsen N, Sundler F, Mulder H. Pituitary adenylate cyclaseactivating peptide is upregulated in sensory neurons by inflammation. Neuroreport 1998;9:2833-6.

[62] Zhang Y, Malmberg AB, Sjolund B, Yaksh TL. The effect of pituitary adenylate cyclase activating peptide (PACAP) on the nociceptive formalin test. Neurosci Lett 1996;207:187-90.

[63] Zhang Y, Malmberg AB, Yaksh TL, Sjölund B, Sundler F, Håkanson R. Capsaicinevoked release of pituitary adenylate cyclase activating peptide (PACAP) and calcitonin gene-related peptide (CGRP) from rat spinal cord in vivo. Regul Pept 1997;69:83-7.

[64] Zhou CJ, Shioda S, Yada T, Inagaki N, Pleasure SJ, Kikuyama S. PACAP and its receptors exert pleiotropic effects in the nervous system by activating multiple signaling pathways. Curr Protein Pept Sci 2002;3:423-39.

[65] Zimmermann M. Ethical guidelines for investigations of experimental pain in conscious animals. Pain 1983;16:109-10. 